RESEARCH PAPER RP1120

Part of Journal of Research of the National Bureau of Standards, Volume 21, August 1938

\title{
DETERMINATION OF BORON IN STEEL AND CAST IRON
}

\author{
By John L. Hague and Harry A. Bright
}

\section{ABSTRACT}

A method is described for the determination of small amounts of boron in steels and irons. The procedure calls for (1) solution of the sample in hydrochloric acid followed by oxidation with hydrogen peroxide, (2) distillation of methyl borate (Chapin's method), and (3) titration of boric acid with sodium hydroxide in the presence of mannite. Selenium and tellurium do not interfere, but germanium, a very minor constituent rarely present in ferrous alloys, causes small positive errors. Directions are given for examining any acid-insoluble material for boron. Data obtained by applying the method to a number of ferrous alloys show that results accurate to \pm 0.002 percent can be expected with irons and steels containing from 0.005 to 0.1 percent of boron.

\section{CONTENTS}

I. Introduction

II. Apparatus and reagents

1. Apparatus

2. Reagents

III. Procedure

IV. Discussion of results

V. References

\section{INTRODUCTION}

The increasing use of boron in the manufacture of metaliurgical products, both as a scavenger and as an alloying constituent, has made desirable an accurate method for its determination when present in small amounts.

The method of Wherry [1], ${ }^{1}$ as modified by Lindgren [2] to apply to the determination of boron in steel, consists essentially in dissolving the sample in a mixture of diluted hydrochloric and nitric acids, precipitating the iron with calcium carbonate, filtering and titrating the boric acid in the filtrate with standard alkali, after adding mannite and phenolphthalein. The titration of small amounts of boric acid in the large final volume and in the presence of large amounts of calcium salts is not entirely satisfactory, a fact noted by others [3].

Tschischewski [4] separated iron from boron by means of the mercury cathode and applied this method to the analysis of iron-boron alloys. The method is not generally applicable to the analysis of iron and steel, because a number of interfering elements are left in solution with the boric acid.

Methods for separating boron from iron, based on direct fusion of the sample in sodium peroxide, are not attractive because small samples

\footnotetext{
1 Numbers in brackets indicate the literature references at the end of this paper.
} 
must be used, and the amount of boric acid involved is difficult to determine accurately. Methods depending on the precipitation of interfering elements by adding sodium or ammonium hydroxide to an acid solution of the alloy are not entirely suitable for the determination of small amounts of boron, since large samples cannot be used conveniently, and it has been shown that boric acid is retained in the precipitate $[1,5]$.

Lundell, Hoffman, and Bright [7] recommend the distillation of boron as methyl borate as directed by Chapin [6]. In this method the volatilized ester, $\mathrm{B}\left(\mathrm{OCH}_{3}\right)_{3}$, is saponified in alkaline solution and the alcohol expelled by evaporation to dryness. The sodium borate is dissolved in water, acidified with hydrochloric acid and the solution boiled to expel carbon dioxide. The excess hydrochloric acid is then neutralized by titration with sodium hydroxide to the methyl red end point. The weak boric acid is next converted to a strong complex acid by the addition of mannite, phenolphthalein added, and the titration continued to the phenolphthalein end point. The boric acid complex with mannite titrates as a monobasic acid under these conditions.

Boric acid can be determined volumetrically with the aid of suitable indicators $[6,8,9,10]$, potentiometrically $[11,12,13,14]$, colorimetrically [18, 19], and gravimetrically as calcium borate [22, 15] or boron phosphate [7].

In the present work, titration with the aid of suitable indicators was adopted as the most desirable method for the determination of boric acid. Consequently, the investigational work dealt chiefly with a study of the conditions suitable for decomposing the sample and distilling the boron. In the procedure adopted, the sample is dissolved in hydrochloric acid and the solution oxidized with hydrogen peroxide. Anhydrous calcium chloride is then added to the solution and the boron is distilled as methyl borate by passing methyl alcohol vapor through the hot solution.

While the procedure may appear somewhat lengthy, a determination can be completed within 3 hours after the apparatus has been assembled and the solutions have been standardized.

The acid-insoluble residue can be examined for boron by filtering the solution remaining after the distillation, igniting the paper and contents under a small amount of diammonium phosphate, and then fusing with sodium peroxide. The melt is then dissolved, and the solution distilled and titrated for boric acid.

\section{APPARATUS AND REAGENTS}

\section{APPARATUS}

The apparatus used is shown in figure 1. It has been described elsewhere $[6,15] . \quad A$ is a U-tube containing mercury, used as a safety trap. $B$ is a $500-\mathrm{ml}$ round-bottomed distilling flask for methyl alcohol, and contains a capillary "boiling tube" of $3-\mathrm{mm}$ bore, the bore being sealed $10 \mathrm{~mm}$ from the lower end. $C$ is a $300-\mathrm{ml}$, round-bottomed flask, $D$ a No. 4 casserole $(360 \mathrm{ml}), E$ a glass condenser, $F$ a $200-\mathrm{ml}$ Erlenmeyer flask, and $G$ a U-tube containing water to prevent the escape of uncondensed methyl borate. The tube leading into flask $C$ 
is flared slightly to avoid plugging by separated salts. The apparatus is assembled with Pyrex glassware and tubing. If very small amounts of boron $(<0.2 \mathrm{mg})$ are in question, an apparatus constructed of a boron-free glass, such as Kavalier glass or fused silica, must be used, and the reagents must be specially purified $[16,17]$.

\section{REAGENTS}

Methyl alcohol.-Alcohol free from boric acid and volatile organic acids must be used. The more nearly anhydrous the alcohol, the better.

Mannite.-Reagent grade, neutral.

Phenolphthalein indicator.-Dissolve $1 \mathrm{~g}$ in $60 \mathrm{ml}$ of ethyl alcohol and dilute to $100 \mathrm{ml}$ with water.

Methyl red indicator.-Dissolve $0.1 \mathrm{~g}$ in $60 \mathrm{ml}$ of ethyl alcohol and dilute to $100 \mathrm{ml}$ with water.

Calcium chloride.-Reagent grade, granular (8 mesh), anhydrous.

Standard solution of boric acid $(0.1 N)$.- Fuse pure boric acid in a

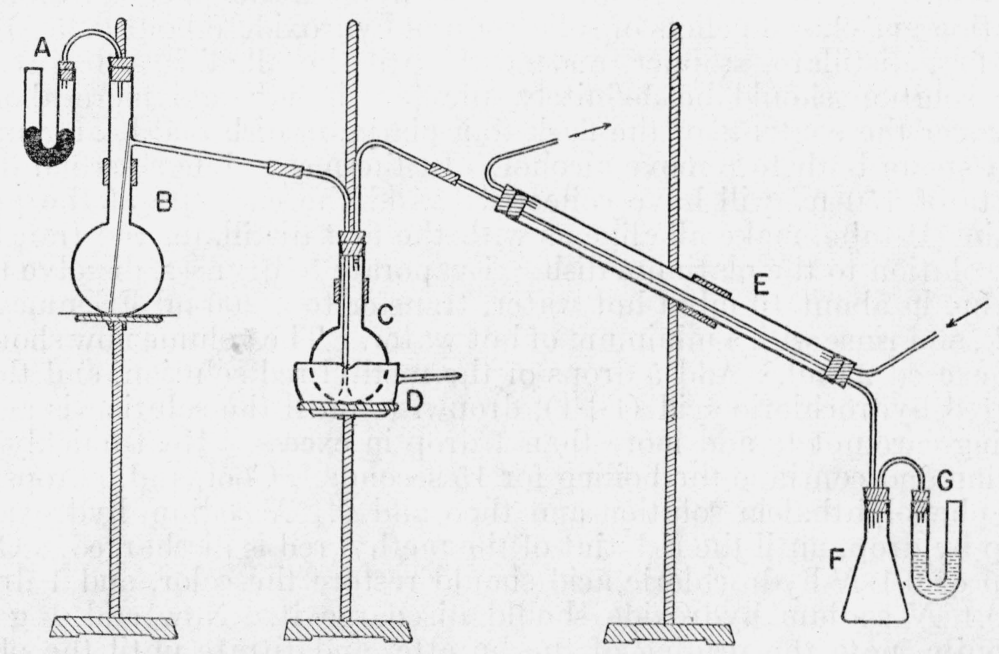

Figure 1.-Apparatus for distilling boron.

platinum dish. While still warm, crush the melt and quickly place the fragments in a weighing tube. Dissolve $3.482 \mathrm{~g}$ in $500 \mathrm{ml}$ of hot, recently boiled distilled water, cool and dilute to exactly $1,000 \mathrm{ml}$. Each milliliter of the solution contains $0.00108 \mathrm{~g}$ of boron.

Standard solution of sodium hydroxide (approximately 0.1 N).-Prepare the solution, as free as possible from carbonates, by diluting $6.5 \mathrm{ml}$ of a clear 50-percent solution of sodium hydroxide with 1 liter of recently boiled distilled water. Standardize by titrating a standard solution of boric acid exactly as described in the recommended procedure.

Hydrochloric acid (approximately $0.1 \mathrm{~N}$ ).-This need be only approximate but should be free from carbon dioxide. 


\section{PROCEDURE}

Transfer a 5-g sample ${ }^{2}$ to a 300-ml round-bottomed fiask. Add $25 \mathrm{ml}$ of hydrochloric acid (sp gr 1.18), insert an air condenser, and heat on the steam bath until the sample is dissolved. Cool, remove the condenser, and add $10 \mathrm{ml}$ of hydrogen peroxide (30 percent), drop by drop as the solution is kept cool. Insert the condenser and heat on a steam bath to decompose the excess peroxide. Cool, and with a minimum of water wash down any condensate in the condenser. Remove the condenser, add $20 \mathrm{~g}$ of anhydrous calcium chloride, ${ }^{3}$ and swirl the contents of the flask to allow the chloride to take up the water. Connect the flask to the apparatus, figure 1, and raise the casserole until the flask dips into the water but does not touch the bottom. Begin the distillation of alcohol from $B$, taking care that the "boiling tube" is functioning properly. After about $25 \mathrm{ml}$ of alcohol has condensed in $C$, heat the casserole with a small flame, keeping it hot enough to prevent condensation in the flask. When a distillate of $150 \mathrm{ml}$ has collected in flask $F$, replace the flask with an empty one and continue the distillation. Add 1 drop of the phenolphthalein solution and 2 or 3 pellets of solid sodium hydroxide (about $0.25 \mathrm{~g}$ ) to the first distillate, stopper, and swirl until the alkali has dissolved. The solution should be definitely alkaline; if not, add more alkali. Transfer the contents of the flask to a platinum dish and heat gently on a steam bath to remove alcohol. In the meanwhile a second distillate of $150 \mathrm{ml}$ will have collected. Add the contents of the protecting U-tube, make alkaline as with the first distillate, and transfer the solution to the platinum dish. Evaporate to dryness, dissolve the residue in about $10 \mathrm{ml}$ of hot water, transfer to a $200-\mathrm{ml}$ Erlenmeyer flask, and rinse with a minimum of hot water. The volume now should not exceed $25 \mathrm{ml}$. Add 5 drops of the methyl red solution, and then diluted hydrochloric acid $(1+1)$, dropwise, until the solution is acid, taking care not to add more than 1 drop in excess. Heat quickly to boiling and continue the boiling for 15 seconds. Cool, add 5 drops of the phenolphthalein solution and then add $0.1 \mathrm{~N}$ sodium hydroxide, drop by drop, until the red tint of the methyl red is discharged. One drop of $0.1 N$ hydrochloric acid should restore the color, and 1 drop of $0.1 N$ sodium hydroxide should discharge it. Now add $1 \mathrm{~g}$ of mannite, note the reading of the burette, and titrate until the phenolphthalein end point appears. Add another gram of mannite, and if the color disappears, continue the titration until the color returns. Continue this process until the addition of $1 \mathrm{~g}$ of mannite does not discharge the phenolphthalein end point.

Correct the volume of $0.1 \mathrm{~N}$ sodium hydroxide required in passing from the methyl red end point to the phenolphthalein end point, by the volume required in a blank run, preferably obtained on a 5-g sample of boron-free iron (such as the National Bureau of Standards Standard Sample 55a) carried through all steps of the method. A uniform blank equivalent to approximately $0.3 \mathrm{mg}$ of boron was obtained on iron 55a with the reagents and Pyrex ware used in this work.

If desired, the acid-insoluble residue can be examined for boron as follows: Dilute the solution remaining after the distillation to a volume of approximately $200 \mathrm{ml}$ and filter through a small paper of close

2 With alloys containing less than 0.005 percent of boron, treat a $10 \mathrm{~g}$ sample with $50 \mathrm{ml}$ of $\mathrm{HCl}$ (sp gr 1.18 ).

3 This amount of $\mathrm{CaCl}_{2}$ also suffices fo ra $10 \mathrm{~g}$ sample, since $\mathrm{FeCl}_{3}$ acts as a desiccant. 
texture and containing a little paper pulp. Wash the paper and residue with hot diluted hydrochloric acid $(1+19)$ and hot water until free from iron salts, and then wash twice with a solution prepared by dissolving $5 \mathrm{~g}$ of ammonium nitrate and $1 \mathrm{~g}$ of diammonium phosphate in $100 \mathrm{ml}$. Add about $0.5 \mathrm{~g}$ of diammonium phosphate to the paper and transfer to a $30-\mathrm{ml}$ ingot iron crucible. Slowly char the paper and then burn the carbon at a temperature of about $450^{\circ}$ to $500^{\circ} \mathrm{C}$. Cool, add $6 \mathrm{~g}$ of sodium peroxide, and fuse for about 3 minutes, or until clear. Cool, and dissolve the melt in a minimum volume of water in a platinum dish. Evaporate the solution to a thick sirup, cool, and transfer to a $300-\mathrm{ml}$, round-bottomed flask. Wash the platinum dish with the amount of hydrochloric acid (sp gr 1.18) needed to neutralize the melt. Keep the flask cool during the transfer and neutralization. Approximately $30 \mathrm{ml}$ of acid will be required, and not more than $1 \mathrm{ml}$ of excess acid should be added. The volume at this point must not exceed $60 \mathrm{ml}$, otherwise the subsequent distillation of boron will be incomplete. Add $50 \mathrm{~g}$ of anhydrous calcium chloride, swirl the flask, and immediately connect to the apparatus. Complete the distillation and titration as already described.

\section{DISCUSSION OF RESULTS}

The accuracy of the results obtained when single determinations by the recommended procedure were made on synthetic samples of irons and steels is illustrated in table 1 . The precision that can be expected is shown in table 2 .

It will be seen from the data given in table 1 that results accurate to about \pm 0.002 percent of boron can be obtained in the analyses of irons and steels containing from 0.005 to 0.1 percent of boron.

TABLE 1.-Results obtained by the recommended procedure on synthetic samples a

\begin{tabular}{|c|c|c|c|c|}
\hline \multirow{2}{*}{ Material } & \multirow{2}{*}{$\begin{array}{l}\text { Weight of } \\
\text { sample }\end{array}$} & \multicolumn{2}{|c|}{ Boron } & \multirow{2}{*}{ Error } \\
\hline & & Added & $\begin{array}{c}\text { Recov- } \\
\text { ered }\end{array}$ & \\
\hline $\begin{array}{l}\text { Ingot iron } 55 \mathrm{a} \\
\text { Do. } \\
\text { Do. } \\
\text { Do. } \\
\text { Do. } \\
\text { Cast iron } 55 \mathrm{a} \text {, plus } 0.5 \mathrm{~g} \text { of steel } 50 \mathrm{a}(3.5 \% \mathrm{Cr}, 1 \% \mathrm{~V}, 18 \mathrm{~W}) \\
18 \mathrm{Cr}-8 \mathrm{Ni} \text { steel } 101 \\
\text { Do }\end{array}$ & $\begin{array}{r}g \\
10 \\
5 \\
2 \\
5 \\
5 \\
5 \\
5 \\
5 \\
5 \\
5\end{array}$ & $\begin{array}{r}\text { Percent } \\
0.005 \\
.022 \\
.055 \\
.055 \\
.109 \\
.044 \\
.033 \\
.022 \\
.044\end{array}$ & $\begin{array}{r}\text { Percent } \\
0.005 \\
.023 \\
.053 \\
.052 \\
.111 \\
.045 \\
.035 \\
.024 \\
.045\end{array}$ & $\begin{array}{r}\text { Percent } \\
\pm 0.000 \\
+.001 \\
+.002 \\
-.003 \\
+.002 \\
+.001 \\
+.002 \\
+.002 \\
+.001\end{array}$ \\
\hline
\end{tabular}

a Spectrochemical examination detected no boron in iron $55 \mathrm{a}$ and steels $50 \mathrm{a}$ and 101 , and less than 0.001 percent in cast iron $A$ in tests that should reveal 0.0005 percent of boron.

b Sample dissolved in $20 \mathrm{ml}$ of diluted hydrochloric acid $(1+1)$.

Spectrochemical examination was made of the irons and steels listed in table 2. In order to compare the results with those obtained by chemical analysis, the logarithm of the intensity ratios for boron $2496.78 \mathrm{~A}$ : iron $2494.00 \mathrm{~A}$ were plotted against the logarithm of the chemical values for boron. A straight line relation was obtained, the agreement indicating that the chemical results, relative to one another, were accurate to \pm 0.002 percent of boron. 
TABLE 2.-Results obtained by the recommended procedure on several steels and irons containing boron

\begin{tabular}{|c|c|c|c|}
\hline Material & $\begin{array}{l}\text { Weight of } \\
\text { sample }\end{array}$ & Boron & $\begin{array}{l}\text { Average } \\
\text { deviation }\end{array}$ \\
\hline Cast iron $B_{\ldots} \ldots$ & $\begin{cases}g & \\
& 5 \\
& 5\end{cases}$ & $\begin{array}{r}\text { Percent } \\
0.017 \\
.013 \\
.014\end{array}$ & $\begin{array}{l}\text { Percent } \\
0.002\end{array}$ \\
\hline Cast iron $C$ & $\begin{array}{l}5 \\
5 \\
5\end{array}$ & $\begin{array}{l}.042 \\
.038 \\
.040\end{array}$ & .001 \\
\hline Mo-Max steel $D \ldots$ & $\begin{array}{l}5 \\
5\end{array}$ & .005 & .001 \\
\hline Carbon steel $E_{-}$ & $\begin{array}{r}5 \\
10 \\
10\end{array}$ & $\begin{array}{l}.018 \\
.017 \\
.019\end{array}$ & .001 \\
\hline Carbon steel $F$ & $\begin{array}{l}5 \\
5 \\
5\end{array}$ & $\begin{array}{l}.057 \\
.061 \\
.060\end{array}$ & .002 \\
\hline Alloy $Q(\mathrm{Co} 40 \%$; Cr 30\%; W $17 \%$; Fe & $\begin{array}{l}1 \\
1 \\
1\end{array}$ & $\begin{array}{l}\text { 8. } 63 \\
\text {. } 61 \\
\text { b. } 62\end{array}$ & .01 \\
\hline
\end{tabular}

a Sample dissolved in $20 \mathrm{ml}$ of diluted $\mathrm{HCl}(1+3)$.

b Sample fused in $6 \mathrm{~g}$ of sodium peroxide and the determination finished as described in the treatment of insoluble residues.

Analysis of the insoluble residues from irons $B$ and $C$ and Mo-Max steel $D$ showed only traces of boron-less than 0.002 percent. Spectrochemical tests of the residues also indicated only minute amounts of boron. The residues from alloy $G$ were not examined for boron, as the agreement between the results obtained by fusion with peroxide and by solution in acid showed that the acid-insoluble residues from this alloy did not contain significant amounts of boron.

The procedure for determining boron in the acid-insoluble residues was tested by adding a portion of National Bureau of Standards Boron Glass No. 93 to the residue from Mo-Max steel $D$. A recovery of 0.019 percent boron was obtained when the equivalent of 0.020 percent boron was added.

Tests were also made to investigate the effect of selenium, tellurium. and germanium in the procedure. No selenium or tellurium could be detected in the distillates and quantitative recovery of boron was obtained after $20 \mathrm{mg}$ of each of the elements was added, as the tetrachloride, to synthetic mixtures of iron 55a and boric acid. Hence, neither of these two elements caused any error in the values obtained for boron. When $20 \mathrm{mg}$ of quadrivalent germanium was added, some of the germanium was distilled with the boron, and in the subsequent titration consumed alkali solution equivalent to approximately $0.5 \mathrm{mg}$ of boron. Quadrivalent germanium forms a complex acid with mannite, and then reacts with alkali in a manner analogous to boron $[20,21]$.

The authors thank Bourdon F. Scribner for making the spectrochemical analyses. 


\section{REFERENCES}

[1] E. T. Wherry, J. Am. Chem. Soc. 30, 1687 (1908).

[2] J. M. Lindgren, J. Am. Chem. Soc. 3\%, 1137 (1915).

[3] T. B. Campbell and H. Fay, Ind. Eng. Chem. 16, 720 (1924).

[4] N. Tschischewski, Ind. Eng. Chem. 18, 607 (1926).

[5] C. M. Johnson, Chemical Analysis of Special Steels, 4th ed., p. 254 (J. Wiley and Sons, 1930.)

[6] W. H. Chapin, J. Am. Chem. Soc. 30, 1691 (1908).

[7] G. E. F. Lundell, J. I. Hoffman, and H. A. Bright, Chemical Analysis of Iron and Steel, p. 390-396 (J. Wiley and Sons, 1931).

[8] A. S. Dodd, Analyst 55, 27 (1930).

[9] F. J. Foote, Ind. Eng. Chem., Anal. Ed. 4, 39 (1932).

[10] E. Schulek and G. Vastagh, Z. anal. Chem. 84, 169 (1931).

[11] J. H. Hildebrand, J. Am. Chem. Soc. 35, 861 (1913).

[12] J. A. M. Van Liempt, Rec. trav. chim. 39, 358 (1920); Z. anorg. allgem. Chem. 111, 151 (1920).

[13] M. G. Mellon and V. N. Morris, Ind. Eng. Chem. 16, 123 (1924); M. G. Mellon and F. R. Swim, Ind. Eng. Chem. 19, 1354 (1927).

[14] L. V. Wilcox, Ind. Eng. Chem., Anal. Ed. 4, 38 (1932).

[15] W. F. Hillebrand and G. E. F. Lundell, Applied Inorganic Analysis, p. 612 (J. Wiley and Sons, 1929).

[16] E. T. Allen and E. G. Zies, J. Am. Ceram. Soc. 1, 763 (1918).

[17] L. F. Rader, Jr., and W. L. Hill, J. Agr. Research (1938) (now in press.).

[18] F. D. Snell and C. T. Snell, Colorimetric Methods of Analysis, p. 526-530 (D. Van Nostrand Co., Inc., 1936).

[19] Gmelins Handbuch der anorg. chem., System-Nummer 13: Bor., p. 36-39, Verlag Chemie G. m. b. H., Leipzig-Berlin (1926) Achte Auflage.

[20] A. Tchakirian, Compt. rend 18\%, 229 (1928).

[21] N. S. Poluektoff, Mikrochemie 18, 48 (1935).

[22] F. A. Gooch and L. C. Jones, Am. J. Sci. [4] \%, 34 (1899).

Washington, May 20, 1938: 